\title{
Unintended consequences of treating early rectal cancers for complete clinical response with chemoradiotherapy
}

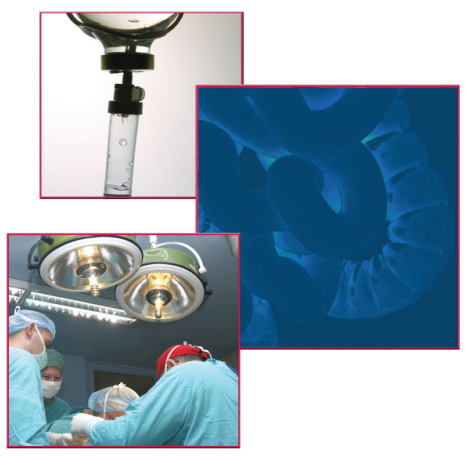

\author{
Rob Glynne-Jones*,1, Neel Bhuva ${ }^{1} \&$ Mark Harrison ${ }^{1}$ \\ ${ }^{1}$ Radiotherapy Department, Mount Vernon Centre for Cancer Treatment, Mount Vernon Hospital, Northwood, HA6 2RN, UK \\ *Author for correspondence: Tel.: +(44) 203826 2434; rob.glynnejones@nhs.net
}

The aim was to examine the current trend in rectal cancer, which is to extend 'watch-and-wait' to earlierstage tumors, not normally treated with chemoradiotherapy, to define the up-side and down-side regarding quality of life (QOL) and anorectal/sexual/urinary function from this approach. We reviewed the literature regarding a 'watch-and-wait' strategy after neoadjuvant chemoradiotherapy. The primary outcome measure was complete clinical response. Secondary measures included colostomy rate, functional outcomes and QOL. There is a trend to use chemoradiotherapy in earlier tumors using dose-escalation of radiation and/or additional chemotherapy, resulting in high rates of complete clinical response, which may impact adversely on QOL if radical surgery is subsequently required. Focusing on organ-preservation as the primary goal of treatment rather than overall functional outcomes and QOL for the whole population, may not provide patients with sufficient information for optimal decision-making.

First draft submitted: 22 August 2019; Accepted for publication: 11 February 2020; Published online: 17 April 2020

Keywords: brachytherapy • chemoradiation • complete clinical response • dose-response • external beam radiotherapy $\bullet$ nonoperative treatment 'watch and wait' organ sparing • preoperative $\bullet$ rectal cancer

The standard curative surgical procedures for patients with rectal cancer include low anterior resection (LAR), abdominoperineal excision (APE) and Hartmann's operation. Neoadjuvant short course preoperative radiotherapy or chemoradiotherapy (CRT), followed by total mesorectal excision (TME) has become the standard treatment options for locally advanced rectal cancer (LARC).

Randomized trials have not demonstrated that the addition of chemotherapy to preoperative radiotherapy improved either disease-free survival (DFS) or overall survival (OS) [1-3]. A further series of randomized trials exploring the addition of oxaliplatin to fluoropyrimidine-based CRT - with the exception of the German CAO/ARO/AIO04 trial [4] - did not report that the addition of oxaliplatin improved outcomes in terms of DFS, with no trials demonstrating an impact on OS [5-9].

Hence, the rationale for offering preoperative CRT rests on reducing local recurrence and improving microscopically margin negative (R0) resection rates. Some suggest preoperative CRT also facilitates the opportunity for sphincter sparing surgery. This view is partly supported by a subset analysis in the German CAO/ARO/AIO-94 trial [10]. Complications of a stoma include impaired sexual function, parastomal herniation, stenosis or retraction of the stoma, in addition to difficulties fitting the bag and leakage. Therefore, most patients wish to avoid a permanent stoma.

These above gains from CRT come at the price of long-term adverse effects from radiotherapy on anorectal, urinary and sexual function. Others therefore argue for a more risk-adaptive policy with better selection of patients for CRT to restrict these toxicities only to patients at high risk of local recurrence [11].

Preoperative CRT also leads to significant tumor regression (downsizing) and downstaging both in the primary tumor and perirectal lymph nodes - with historical data reporting 10-20\% of patients achieve a pathological complete response (pCR). A pCR is associated with low rates of local recurrence and excellent long-term survival [12]. Patients with clinically staged cT1 and cT2 rectal cancers according to current imaging with magnetic resonance imaging (MRI), have very high rates of pCR after CRT in the region of 30-40\% [12]. Many patients also achieve

Future Medicine 
a clinical complate response (cCR) after CRT and are considered appropriate for a 'watch and wait' nonoperative approach. For this reason, many argue that patients may have better QOL by administering CRT and avoiding the consequences of radical surgery.

However, $25 \%$ of tumors undergo minimal regression after CRT and 40\% show intermediate responses, with varying degrees of residual viable tumor, but only responding patients seem to benefit in terms of survival [13].

In the German CAO/ARO/AIO-94 trial, patients were randomized to preoperative or postoperative chemoradiation. OS was identical in each arm. Yet, both complete and intermediate tumor regression grade (TRG) - based on the Dworak classification - after CRT, appear to be associated with improved long-term outcomes [14]. 10-year cumulative incidence of distant metastasis and DFS were 10.5 and $89.5 \%$ for patients with TRG 4 (complete regression), $29.3 \%$ and $73.6 \%$ for TRG 2 and 3 (intermediate regression) and 39.6 and $63 \%$ for TRG 0 and 1 (poor regression), respectively ( $\mathrm{p}=0.005$ and $\mathrm{p}=0.008$ ). Ergo only patients who achieved an excellent response benefited and it is likely that nonresponders were negatively impacted by CRT, since OS was identical in each arm [15].

Until now, this selection for 'watch and wait' has relied on characteristics such as frailty, elderly age, comorbidities and personal preferences. Novel therapeutic strategies aim to increase the likelihood of PCR and cCR by intensification in the neoadjuvant setting, with dose-escalating radiotherapy, additional chemotherapy or the incorporation of novel agents, such as in the Total Neoadjuvant Therapy Trial (TNT; ClinicalTrials.gov identifier: NCT02921256).

The TNT philosophy has been extended to deliver neoadjuvant FOLFOX and CRT to smaller, earlier stage cancers (where neither is usually indicated oncologically), with the aim of increasing the rates of cCR and pCR. The argument runs that, although surgery is the standard treatment, a 'watch-and-wait' strategy is reasonable in these selected patients if a cCR is achieved. Hence, pCR and cCR appear to have become worthy end points in their own right, which have been accepted as surrogate end points for better outcomes in LARC. Many trials are now being performed to increase pCR rates by modifying the available preoperative treatment strategies [16], based on previous data with induction or consolidation chemotherapy strategies [17].

Categorization, according to the degree of response to preoperative CRT in rectal cancer, defines long-term outcomes whether by down-staging according to ypTNM, pathological TRG [14,18], neoadjuvant rectal (NAR) score $[19,20]$ and a simple, complete, intermediate or poor clinical response [21]. Although the outcomes appear less favorable for patients down-staged to yp stage I [22] or II [23] when compared with the same pathological stage after surgery alone. Poor response to CRT is associated with significantly worse outcomes. Yet, there is rarely any suggestion that these patients with poor response after CRT may be disadvantaged by treatment, which has proved ineffective.

In the EORTC 22921 trial, the addition of 5-fluorouracil (5-FU) radiation tripled the rate of pCR [24], but CRT did not mean more patients were cured compared with radiotherapy alone, in other words, pCR is not a surrogate for improved OS at the trial level. Either a pCR may simply be observed in patients who have an excellent prognosis anyway, and would have been cured by radiotherapy alone, or the additional $10 \%$ of patients who achieve a pCR with CRT are balanced by $10 \%$ of patients who are poor responders and whose outcome could be actually worsened by CRT. CRT leads to cytotoxic DNA damage, which can be either repaired or partially repaired. In such case, residual surviving cells after CRT can acquire better capacity for repair if additional treatment is subsequently required [25]. Hypoxia, epithelial-mesenchymal transition, invasiveness and tumor motility, may be enhanced in residual resistant tumor cells [26], which in turn predicts a more resistant tumor [27]. LCCRT also enriches the residual tumor with CD133 stem like patterns, which are recognized to be more resistant to subsequent 5-FU. Intratumoral genetic heterogeneity is reported to be enhanced by LCCRT, leading to more frequent mutations after treatment in resistant tumors compared with baseline ( 92.9 vs $7.1 \%$; $<<0.00001)$. Some of these genetic mutations are associated with genetic instability and drug resistance [28]. These mutations were not detected prior to treatment.

There is also upregulation/enrichment of cancer cells expressing the stem cell marker CD133 following 5FU-based preoperative LCCRT [29]. These upregulated $\mathrm{CD} 133^{+}$cancer cells correlate with an increased risk of distant recurrence and decreased survival [30]. In a study of adjuvant 5-FU in curatively resected stage III colon cancer, patients with $\mathrm{CD} 133^{+}$cells showed resistance to 5-FU-based chemotherapy, while CD133-negative patients experienced significant survival benefits from adjuvant chemotherapy when compared with CD133-positive patients [31]. Hence, it is feasible that patients who do not require CRT and fail to respond to this combination could be disadvantaged and experience worse outcomes. 
There is an increasing number of publications regarding 'watch and wait' and organ preservation. Yet, despite this topic being a common source of research and reviews, many clinicians do not feel comfortable discussing this strategy with patients [32]. If a more liberal approach for the use of CRT or radiotherapy is commonly adopted, extending beyond the standard oncological indications for the use of radiotherapy, then joint decision-making could become even more difficult to achieve. If the aim of using CRT is simply to avoid surgery, patients who do not achieve cCR or suffer unintended consequences from regrowth and require radical surgery as salvage, may actually be compromised in terms of QOL. They will have experienced the compounding side effects of both radical CRT and radical surgery - so called 'double jeopardy'. Rather than just offering a possible strategy to avoid radical surgery (which many patients will gladly accept), we also need to clarify to what extent this strategy will increase both oncological and functional risks.

We have reviewed a 'watch and wait' approach previously [33]. In this present report, we focus on defining the potential advantages and disadvantages of extending CRT and a 'watch and wait' strategy to smaller earlier-stage cancers in the mid rectum, usually treated by radical surgery alone. The primary outcome measure was cCR. Secondary outcome measures included LRF, the rate of metastases, DFS and OS, permanent stoma rate, functional outcomes and QOL.

We hypothesized that $30-40 \%$ of patients with cT2/cT3a/b would avoid major surgery if they received CRT, but this advantage would be traded off against a permanent colostomy/ileostomy rate of $30 \%$ and major low anterior resection syndrome (LARS) in those $30 \%$ of patients with an intact sphincter. This range of outcomes would compare with a permanent colostomy of $10 \%$ and major LARS in $20 \%$ after LAR alone. We provide an algorithm from this evidence (Table 1), which may be useful in discussions and subsequent decision-making for patients with rectal cancer.

The basis for the 'watch and wait' approach is founded on mainly retrospective single institution experiences. In the original report, a total of 36/118 (30\%) achieved a cCR using the 'watch-and-wait' approach [43]. Subsequent papers from the same institution [34,44] have refined the results and the methodology more clearly. The Habr Gama Brazilian protocol has been modified with the doses of radiotherapy escalated to 54 Gy. They also deliver three cycles of 'adjuvant' 5-FU-based chemotherapy after CRT before assessment at 10 weeks. cCR rates of $47 \%$ appearing achievable [45]. Other small institutional retrospective studies [46,47], propensity score-matched cohort analyses [48] and modest population databases (less than 5000 patients [49] support the strategy). There have been several meta-analyses [50-52]. We identified few prospective [17] and no relevant randomized trials. Some excellent and informative randomized trials have been planned [53,54], but have either not been completed or are unpublished.

Retrospective studies demonstrate that a proportion of patients with LARC achieve a cCR after CRT and in the majority of these fortunate patients, $\mathrm{CCR}$ is sustained long-term and they never require a standard radical surgical procedure, TME.

The lack of prospective studies means that a large number of patients achieving cCR is recognized [50], but not the denominator, for example - the total number of patients required to be treated with CRT in order to achieve this proportion of cCR. Various series have reported a cCR rate, which varies from $11 \%$ to $47 \%[45,55]$.

A recent report of a prospectively maintained database of patients, selectively treated with neoadjuvant radiotherapy (45-50.4 Gy and 25 Gy) with moderate or high-risk features for local recurrence on MRI, demonstrated that patients achieved a cCR after CRT in $63 \%$ of cases [56]. In a series from Portugal, most received a simultaneous integrated boost up to 54-56 Gy to involved areas. If medically fit and considered high-risk for distant metastases, patients also received consolidation chemotherapy 4-6 weeks after completion of radiotherapy. They received XELOX i.e. oral capecitabine $\left(1000 \mathrm{mg} / \mathrm{m}^{2}\right.$ twice daily (on days $1-14$ of each cycle) plus intravenous oxaliplatin $\left(130 \mathrm{mg} / \mathrm{m}^{2}\right.$ on day 1 of each cycle) every 3 weeks. The aim was to deliver six 3 -weekly cycles. This very high cCR rate mirrors Habr Gama's more recent experience [45], but in a clinically more adverse group with selective criteria on MRI for more advanced tumors with high risk features.

Although the data provided are encouraging for the 'watch and wait' approach, in terms of the feasibility and oncological safety for patients with LARC (who require neoadjuvant CRT), there is no randomized evidence and the quality of these data remain at best preliminary.

Controversy remains as to how to define these patients with some confidence at an early stage after CRT in order to avoid surgery. Protocols have been devised with clinical and radiological criteria to define a clinical response. Close surveillance appears to permit early detection of predominantly endo-luminal local recurrences, which can be salvaged surgically with little additional risk to the patient $[57,58]$. 
Table 1. Potential outcomes after radical surgery or CRT for CT2cT3a mid rectum $(6-9 \mathrm{~cm})$ not initially requiring APER.

\begin{tabular}{|c|c|c|c|c|c|c|}
\hline TME Surgery alone & $\begin{array}{l}\text { CRT leading to CCR } \\
\text { no surgery required }\end{array}$ & Regrowth after CCR & $\begin{array}{l}\text { CRT non CCR treated } \\
\text { with TEM }\end{array}$ & $\begin{array}{l}\text { CRT and non CCR or } \\
\text { regrowth requiring } \\
\text { standard TME }\end{array}$ & $\begin{array}{l}\text { CRT and non CCR or } \\
\text { regrowth requiring } \\
\text { APER }\end{array}$ & Ref. \\
\hline $\begin{array}{l}100 \% \text { radical surgery } \\
\text { if TME alone selected } \\
\text { and no RT (? unless } \\
\text { metastases discovered } \\
\text { at laparotomy) }\end{array}$ & $\begin{array}{l}35-50 \% \text { achieve CCR } \\
\text { after CRT (Habr Gama } \\
\text { 2011) }\end{array}$ & $15-20 \%$ & $5-120 \%$ & $20 \%$ & $25 \%$ & [34] \\
\hline $\begin{array}{l}\text { Permanent } \\
\text { Colostomy Not } \\
\text { usually required } \\
\text { - unless very narrow } \\
\text { pelvis and difficult } \\
\text { surgery - particularly } \\
\text { anteriorly. } \\
\text { Not considered } \\
\text { necessary to perform } \\
\text { a defunctioning } \\
\text { ileostomy if CRT not } \\
\text { given }\end{array}$ & $\begin{array}{l}80 \% \text { of the above } \\
\text { sustained CCR (no } \\
\text { stoma assumed in } \\
\text { vast majority but? } \\
\text { late effects as in anal } \\
\text { cancer may mean few } \\
\text { require defunctioning } \\
\text { stoma to deal with } \\
\text { symptoms) }\end{array}$ & $\begin{array}{l}15-20 \% \text { regrowth } \\
\text { requiring TEM TME or } \\
\text { APER (Habr Gama) }\end{array}$ & $\begin{array}{l}10 \% \text { salvaged by TEM } \\
\text { But } 5 \% \text { adverse } \\
\text { features advised to } \\
\text { undergo completion } \\
\text { TME and } 3 \% \\
\text { subsequently relapse }\end{array}$ & $\begin{array}{l}\text { Need a defunctioning } \\
\text { stoma }(100 \%) \text { for } \\
\text { TME. } \\
\text { Requires second } \\
\text { operation for closure } \\
\text { APER }(30 \%)\end{array}$ & $\begin{array}{l}\text { Permanent stoma in } \\
100 \%\end{array}$ & \\
\hline $\begin{array}{l}\text { No defunctioning } \\
\text { stoma - hence one } \\
\text { operation only }\end{array}$ & $\begin{array}{l}\text { No operation at all } \\
\text { required if sustained } \\
\text { CCR }\end{array}$ & $\begin{array}{l}\text { If TME (likely in } 50 \% \\
\text { of regrowths ie } 10 \% \\
\text { overall) will need } \\
\text { defunctioning stoma } \\
\text { ie } 10 \% \text { need two } \\
\text { operations }\end{array}$ & $\begin{array}{l}30 \% \text { may fail and } \\
\text { require subsequent } \\
\text { TME } \\
\text { ie., } 2-5 \% \text { two } \\
\text { operations, TME or } \\
\text { APER }\end{array}$ & $\begin{array}{l}\text { ie., } 10 \% \text { two } \\
\text { operations for } \\
\text { patients able to have } \\
\text { TME }\end{array}$ & $\begin{array}{l}\text { Permanent stoma in } \\
100 \%\end{array}$ & \\
\hline $\begin{array}{l}\text { You could have a leak } \\
\text { which might mean a } \\
\text { stoma (probably only } \\
5 \% \text { in early tumours) } \\
5 \% \text { defunctioning } \\
\text { stoma so very few } \\
\text { ( } 2 \% \text { overall) fail to } \\
\text { have stoma reversed }\end{array}$ & $\begin{array}{l}\text { Not applicable. No } \\
\text { radical surgery so no } \\
\text { leak }\end{array}$ & $\begin{array}{l}4 \% \text { fail to have stoma } \\
\text { reversed }\end{array}$ & $\begin{array}{l}20-30 \% \text { of ileostomy } \\
\text { stomas never restored } \\
\text { (Dutch data, NBOCA) } \\
\text { le } 12 \% \text { overall fail to } \\
\text { have stoma reversed. } \\
\text { Stoma occasionally } \\
\text { required for poor } \\
\text { healing/pain }\end{array}$ & $\begin{array}{l}25-30 \% \text { of ileostomy } \\
\text { stomas never restored } \\
\text { (Dutch data, } \\
\text { NBOCA 2019) }\end{array}$ & $\begin{array}{l}\text { Permanent stoma in } \\
100 \%\end{array}$ & [35] \\
\hline $\begin{array}{l}\text { Total requiring stoma } \\
2-10 \%\end{array}$ & $\begin{array}{l}<2 \% \text { if no major } \\
\text { surgery }\end{array}$ & $\begin{array}{l}\text { TME in } 50 \% \\
\text { APER in } 30 \% \\
\text { Local excision } 10 \% \\
\text { Unresectable/ } \\
\text { unsalvageable } 5-7 \%\end{array}$ & $\begin{array}{l}\text { APER required for } \\
\text { adverse histology or } \\
\text { later recurrence } 25 \% \\
12 / 47 \text { (Vereseveld } \\
2015 \text { ) }\end{array}$ & $20-30 \%$ & $\begin{array}{l}\text { Permanent stoma in } \\
100 \%\end{array}$ & [36] \\
\hline $\begin{array}{l}\text { Mortality } 1-2 \% \text { if } \\
\text { elective and under } 80 \\
2-4 \% \text { in elderly or } \\
\text { frail }\end{array}$ & $\begin{array}{l}0.7-2 \% \text { mortality } \\
\text { after preop CRT prior } \\
\text { to surgery (Roh 2009, } \\
\text { Bujko 2004) }\end{array}$ & $\begin{array}{l}1-2 \% \\
\text { Less if local excision }\end{array}$ & $\begin{array}{l}0.7-2 \% \text { mortality } 4 \% \\
\text { in frail (Vereseveld } \\
2015 \text { ) }\end{array}$ & $\begin{array}{l}1-2 \% \text { mortality, } 4 \% \\
\text { in frail }\end{array}$ & $\begin{array}{l}1-2 \% \text { mortality, } 4 \% \\
\text { in frail }\end{array}$ & [36-38] \\
\hline $\begin{array}{l}\text { Chronic Pain in } 25 \% \\
\text { surgery alone } \\
\text { (Feddern 2015) }\end{array}$ & No data & No data & $\begin{array}{l}\text { Pain from healing } \\
3-6 \text { months }\end{array}$ & $\begin{array}{l}\text { Pain in } 40 \% \text { (Feddern } \\
2015 \text { ) }\end{array}$ & $\begin{array}{l}\text { Pain in } 40 \% \text { (Feddern } \\
2015 \text { ) }\end{array}$ & [39] \\
\hline $\begin{array}{l}\text { Local recurrence is } \\
\text { less than } 3 \%\end{array}$ & None & $3-10 \%$ & $3-10 \%$ & Unsalvaged LR 4-7\% & Unsalvaged LR 4-7\% & \\
\hline $\begin{array}{l}\text { Overall survival is } \\
87-92 \% \text { (refs) }\end{array}$ & No data for cT2 & No data & No data & $\begin{array}{l}\text { OS could be worse } \\
\text { because RT } \\
\text { unnecessary (Van Gijn } \\
\text { 2011) and two } \\
\text { operations }\end{array}$ & $\begin{array}{l}\text { OS could be worse } \\
\text { because RT } \\
\text { unnecessary for R0 } \\
\text { rescetion (Van Gijn } \\
\text { 2011) and two } \\
\text { operations }\end{array}$ & [40] \\
\hline $\begin{array}{l}\text { Late radiation effects } \\
\text { (ulcer etc) None }\end{array}$ & $\begin{array}{l}\text { I have not seen data - } \\
\text { but it must exist even } \\
\text { with } 45 \mathrm{~Gy} \text {. }\end{array}$ & $\begin{array}{l}5-10 \% \text { late } \mathrm{G} 3 \\
\text { toxicity }\end{array}$ & $\begin{array}{l}<10 \% \text { ulcers fail to } \\
\text { heal and require } \\
\text { stoma/radical surgery }\end{array}$ & $\begin{array}{l}5-10 \% \text { late } \mathrm{G} 3 \\
\text { toxicity }\end{array}$ & $\begin{array}{l}\text { ? less as no } \\
\text { anorectum }\end{array}$ & \\
\hline $\begin{array}{l}\text { LARS }>6 \mathrm{~cm} \text { if } \\
\text { surgeon leaves } \\
\text { sufficient: } \\
\text { Major } 3 \% \\
\text { Minor } 17 \% \\
\text { None } 80 \%\end{array}$ & $\begin{array}{l}\text { CRT no data for CT2 } \\
\text { No data for } 5 \times 5 \mathrm{~Gy}\end{array}$ & $\begin{array}{l}\text { Major } 80 \% \\
\text { (Bondeven 2015) }\end{array}$ & $\begin{array}{l}\text { - Major Lars in } 50 \% \\
\text { - Minor } 28 \% \\
\text { - None } 22 \% \text { (Stijns } \\
2019 \text { ) }\end{array}$ & $\begin{array}{l}\text { - Major Lars in } 50 \% \\
\text { - Minor } 28 \% \\
\text { - None } 22 \%\end{array}$ & $\begin{array}{l}\text { - Major Lars in } 50 \% \\
\text { - Minor } 28 \% \\
\text { - None } 22 \%\end{array}$ & {$[41,42]$} \\
\hline HR QOL & $\begin{array}{l}\text { Good (but not } \\
\text { perfect) }\end{array}$ & $\begin{array}{l}\text { Worse than after CRT } \\
\text { and local excision }\end{array}$ & $\begin{array}{l}\text { Equal to baseline, } \\
\text { with improved } \\
\text { emotional well-being } \\
\text { in patients treated } \\
\text { with TEM }\end{array}$ & $\begin{array}{l}\text { Acceptable but } \\
\text { adapted }\end{array}$ & $\begin{array}{l}\text { Acceptable but } \\
\text { adapted }\end{array}$ & \\
\hline
\end{tabular}


However, meticulous and assiduous follow-up surveillance is necessary and patients unable to comply with this constraint may be disadvantaged. The clinical assessments (inspection, palpation and MRI) are imperfect and although most effective in low rectal tumors within access of the finger at DRE, there is significant inter-rater variability to all these tests. The ultimate arbiter is histological examination of the whole mesorectum, but this assessment requires an entire surgical specimen, which cannot be replaced in the patient if no tumor cells are identified. Waiting longer may confirm or deny the surgeon's instinct that a CCR has been achieved [58].

Some trials suggest radical surgery results in a permanent stoma in $10-30 \%$ of patients with low rectal cancer and up to $20 \%$ after LAR [59]. In the UK, $35 \%$ of patients undergoing elective major resections for rectal cancer still have a stoma in place at 18 months. This figure excludes those planned for APE [35].

Our goals as oncologists for selecting the most appropriate treatment for the individual patient in front of us, are either to extend their OS and DFS, to improve their health-related QOL- or at the very least prevent or limit a deterioration in their QOL. However, in view of the varying outcomes described above, the individual is likely to have their own preferences to balance and prioritize survival against QOL issues such as a permanent stoma, functional loss and ongoing treatment-related symptoms. Hence, choices are always going to be challenging.

A 'watch and wait' policy appears safe in patients where preoperative CRT was indicated for oncological reasons, in terms of the ability to salvage non-responders and their ultimate survival [49]. What remains unclear is the long-term functional outcomes both of those that achieve organ-sparing after CRT and those who fail to respond and resort to radical surgery. This information is particularly pertinent for those patients who did not require CRT initially - especially if treatment has been escalated either in term of radiotherapy doses, or chemotherapy in a TNT approach.

TNT strategies have been widely adopted in the USA because the additional FOLFOX chemotherapy appears to enhance tumour regression and increases both the proportion of patients who achieve a PCR and also a cCR or near-cCR. The TNT philosophy has been extended to argue that, although surgery is the international standard treatment for rectal cancer, a 'watch-and-wait' strategy is reasonable for selected patients if a cCR is achieved. This rationale of TNT has recently been extended to increasing the chance of avoiding surgery altogether, in a non-operative or 'watch and wait' strategy [60]. This aim is focused on increasing the rates of cCR and pCR and underpins the current US TNT approach [61].

The strategy of radiotherapy or CRT, first followed by chemotherapy, appears to be associated with very high pCR rates [17]. If the residual cells after CRT can repair and survive, they are more able to repair subsequent damage and are selected for more aggressive clones with more epithelial mesenchymal transition (EMT) and more resistance. However, there may be a window of opportunity where additional chemotherapy may be able to nudge these patients from a sublethal damage that can be repaired into irretrievable cell death. Hence, the total radiotherapy dose and fractionation of the CRT component may be more critical than is currently imagined.

There is also a widely accepted assumption (which is not yet supported by data) that cytotoxic treatment in the neoadjuvant setting, may decrease the risk of distant metastases for the patient, possibly by eliminating circulating tumor cells, if the viability of the primary tumor is compromised [62]. However, if cT2/cT3 cancers are treated benefit in terms of systemic effects, reduction of subsequent metastatic spread would seem inherently unlikely. Delivery of systemic chemotherapy at standard doses before rather than after surgery is expected to enhance compliance [63].

Proponents argue that a different set of rules applies to earlier smaller tumors, since the likelihood of achieving cCR after CRT is much higher, will occur earlier, will be more clear-cut, easier to determine with certainty and is more likely to be sustained long term. Some have claimed that up to $50 \%$ of cT2 or early cT3 tumors may not need radical surgery $[45,64]$. However, the current move to promote and offer this strategy to all patients with earlier cT2/cT3a tumors, where radiotherapy is not usually indicated, may have unintended consequences.

Given the lack of evidence from randomized clinical trials, many members of the multidisciplinary team, who regularly counsel patients, may not feel comfortable in discussing 'watch and wait' with patients, since it remains unclear regarding the advantages and disadvantages of this approach.

Studies in 'watch and wait' and organ preservation focus on the happy few who achieve a cCR and avoid a permanent stoma, but there is less information on the clinical and functional outcomes in those who fail to do so and require major surgery [48]. The expected stoma rate in this latter group has rarely been reported [42].

Although the majority of patients who experience a regrowth do so within the first 12 months, there may not be a clear plateau after which local regrowth is unusual and monitoring can cease [60]. Although the majority of regrowth's occur within 3 years, some are still reported after 5 years, hence, surveillance and imaging need to 
continue for at least 7 years, which may also impact on QOL. This retrospective study of patients with rectal cancer treated via a 'watch and wait' strategy off-protocol at the Memorial Sloan Kettering Cancer Center (NY, USA) also questions whether patients who had local regrowth had a higher risk of metastases compared with those who did not have local regrowth (36 vs $1 \%$; p < .001) [60] and poorer survival if they have been nudged into a cCR by additional treatment over and above standard CRT and subsequently experience regrowth. However, poorer survival in the 'watch-and-wait' group may simply reflect selection of older patients with more comorbidity, who were not considered sufficiently fit for radical surgery.

Few reports compare clinical outcomes for patients treated with CRT, who fail to achieve a cCR and are resected with patients who achieve an initial CCR but fail to maintain this and eventually develop tumor regrowth, which requires deferred radical surgery [56]. When operated by high quality surgeons, a regrowth does not appear to confer additional oncological risks, but data regarding function and QOL are sparse.

Considerable information is available on the risk of distant metastases, intraluminal regrowth and subsequent surgical salvage [52]. In this meta-analysis, the relative risk of overall mortality in the salvage therapy group was 2.42 (95\% CI 0.96-6.13) compared with the group who had conventional surgery, but this was not statistically significant $(\mathrm{p}>0.05)$. There are no data on surgical morbidity, late radiation effects and functional outcomes after salvage surgery for those who did not benefit from the 'watch-and-wait' approach, however, a permanent colostomy is usually required in at least $50 \%$ of patients [50].

Due to the widespread use of screening in the UK, there has been a reduction in average tumor size and stage at diagnosis. Patients with cT2N0 or cT3aN0 are more likely to achieve pCR [65,66], or cCR following CRT [66,67], which is more likely to be sustained. Higher rates of cCR may be achieved with escalation of radiotherapy dose [31,45] or additional consolidation chemotherapy [17,68], although, this improvement is less likely in cT3 cancers [69].

Early stage and small tumors are less likely to have nodal involvement, which may enhance the likelihood of achieving a CCR and lessen the risk of regrowth. The risk of fragmentation after CRT is avoided unless extramural vascular invasion or extranodal deposits are present. However, with increasing use of radiotherapy in early tumors, diagnosed at a younger age as a result of screening and greater awareness, the late consequences of radiation become ever more pertinent. Although the mantra "non-surgical management of rectal cancer is increasingly gaining acceptance as it avoids extirpative surgery and a stoma" only tells half the story.

We need prospective randomized data, but we have used the following mainly retrospective data to construct the tables attached.

\section{Evidence from standard doses of chemotherapy \& radiotherapy Mortality after radical surgery}

If emergency cases are excluded, even in otherwise healthy patients the mortality rate after TME is at least $1-2 \%$ and this may be even higher in older adults [70].

\section{Consequences of radical surgery with \& without radiotherapy}

Radiotherapy reduces the functional outcomes after radical surgery in approximately $15 \%$ of patients over surgery alone, whether in the low or mid rectum [71]. The LARS score was developed to capture reporting of LARS and assessing bowel dysfunction [72] and demonstrated that $80 \%$ experience major LARS after the combination of CRT and LAR.

Patients who underwent local excision had a better QOL and bowel function than those who underwent mesorectal excision, although function was compromised if a TME had to be performed after local excision [73]. It seems likely to the present authors that If CRT is given and a 'watch-and-wait' program embarked, then local excision should be more feasible as a curative maneuver for early cT2/T3a tumors after regrowth, than more advanced tumors (cT3/T3d or T4).

APE completely removes distal colon, rectum and anal sphincter complex, resulting in a permanent colostomy. A permanent colostomy is required in $10-30 \%$ of patients in cancers close to the anal verge and involving the sphincter mechanism. APE is associated with significant physical and psychological morbidity [74] and alteration in body image. Most, but not all patients express a strong preference to avoid a colostomy.

Surgical morbidity ranges from 6 to 35\%. LAR has several possible consequences which include: anastomotic leaks, pelvic sepsis, blood loss, autonomic nerve damage leading to urinary incontinence or retention, sexual dysfunction and faecal incontinence, with variable severity and chronic pain. APE is likely to involve all of the 
above and also a permanent stoma. In addition, a symptomatic anastomotic leak (5-10\%) invariably results in a permanent stoma and OS is decreased [75].

If a LAR is performed after CRT, ileostomy or colostomy is invariably performed to reduce the consequences of anastomotic leak [76] and $20-40 \%$ of these are never reversed [77,78]. Ileostomy confers considerable morbidity in up to $60 \%$ of patients [79] and has a negative impact on QOL [80]. A meta-analysis suggested that $30 \%$ of patients develop a hernia after stoma closure [81]. Therefore, after CRT, even if a LAR is performed, $20-30 \%$ of patients retain a permanent stoma [82].

\section{Morbidity, functional outcomes \& consequences}

Data on morbidity and functional outcomes after CRT alone or after CRT and salvage surgery in early cancers are lacking.

\section{Outcomes after regrowth following a 'watch-\&-wait' policy}

A recent meta-analysis reflects outcomes for locally advanced tumors with high-risk characteristics $(2 / 3$ had T3 rectal tumors), where CRT was considered necessary to achieve a curative resection and reduce the risk of local recurrence.

\section{Permanent stoma risk}

Patients who achieved a cCR and are managed by the 'watch and wait' approach had a 3-year colostomy-free survival of $74 \%$ [48]. It should be noted that a definitive colostomy may be the inevitable consequence of salvage surgery in at least $50 \%$ of patients.

\section{Anorectal function}

Functional outcomes of patients managed with CRT without radical surgery are likely to be better than outcomes of the combination of CRT and radical surgery or CRT and local excision [45,83]. QOL after CRT in a 'watch-and-wait' approach appears better than after the combination CRT and TME [84]. However, it is recognized that patients who achieve a cCR and avoid radical surgery may not have perfect function [84,85]. A small retrospective study with 33 patients treated with an organ sparing approach and a median time from CRT completion to assessment of 38 months (range 23 to 117), reported major LARS in 33\%, minor LARS in 30\% and no LARS in 36\% of patients [86].

In the FOWARC study, 220 patients responded to a questionnaire (median follow-up 40.2 months), of whom 119 (54.1\%) reported major LARS, 74 (33.6\%) reported minor LARS and 27 (12.3\%) reported no LARS. Compared with the neoadjuvant chemotherapy alone, the CRT group reported significantly more major LARS (64.4 vs 38.6\%, respectively; p < 0.001) and worse QOL [87].

\section{Quality of life}

The increasing life expectancy of rectal cancer survivors highlights the relevance of long-term functional outcomes and QOL in decision-making. Only seven randomized trials provide data on QOL [88-94]. Few patients admit to major problems, despite marked functional changes. However, reports from the Dutch TME trial suggest many patients have poor anorectal function after TME [95]. Major LARS has a clear, negative impact on global health. Preservation of anorectal function and avoidance of LARS is likely to improve QOL [96].

The National Surgical Adjuvant Breast and Bowel Project (NSABP; PA, USA) Protocol R-04 trial, randomized 1608 patients (2004-2010) between four different neoadjuvant CRT regimens. A report used patient-reported outcomes (PROs) to measure QOL at baseline, after CRT and only one year after surgery [93]. The QOL questionnaires included the Functional Assessment of Cancer Therapy for patients with colorectal cancer (FACT-C) and the European Organization for the Research and Treatment of Cancer module for patients with colorectal cancer (EORTC-QLQ-CR38). There was no difference on overall QOL as measured by the FACT-C total score between the APE and sphincter sparing surgery groups at one year after surgery. Interestingly, $43.3 \%$ of those intended to undergo sphincter sparing, in the event underwent APE. However, APE patients reported worse body image (70.3 vs $77.0 ; \mathrm{p}=0.0005)$ and worse micturition symptoms (26.9 vs $21.5 \% ; \mathrm{p}=0.03$ ) than the sphincter sparing surgery group at 1 year. Both males and females undergoing APE reported worse sexual enjoyment at 1 year, when compared with LAR. For the stoma-related problems symptom scale, patients who underwent sphincter sparing surgery with ileostomy, reportedly had worst symptoms (41.4) when compared with sphincter sparing surgery 
patients with colostomy (34.0) or APE (34.9\%), but this difference was not statistically significant. It is difficult not to speculate that these symptoms resulting from radiotherapy will worsen over time.

A stoma appears to confer a lower QOL among patients with rectal cancer [97]. However, no differences in QOL were reported when endoluminal loco-regional resection using trans-anal endoscopic microsurgery (TEM) to laparoscopic total mesorectal excision (LTME) at the time point of 3 years [98].

\section{Urinary \& sexual function}

It is also recognized that sexual and urinary dysfunction are common after radiotherapy and radical surgery [99,100] such that approximately $40 \%$ of patients have a degree of urinary dysfunction, while $10-70 \%$ suffer with impaired sexual function. Sexual dysfunction typically comprises impotence or the inability to ejaculate in males and, vaginal dryness and dyspareunia in women. The issue is complicated by other factors such as poor body image after surgery, depression, fatigue post radiotherapy and loss of independence, which all contribute to perceived sexual dysfunction. However, The Dutch TME trial demonstrated that there was a non-statistically significant reduction in male sexual activity (from 100\% pre-operatively) with 67 versus $76 \%$ post surgery in irradiated and nonirradiated patients respectively. In females the difference was 72 versus $90 \%$, respectively [101].

In the German pre- versus post-operative radiotherapy studies, $2-4 \%$ of patients reported long term bladder issues [102]. A randomized trial in unresectable or recurrent rectal cancers (i.e., very advanced cases) included 207 patients and examined self-reported late effects using EORTC QLQ30, IIEF and SVQ questionnaires. Patients received $50 \mathrm{~Gy} / 25$ \# with or without 5-FU/leucovorin. Overall, 25\% reported some urinary dysfunction. Severe erectile dysfunction was seen in the vast majority of male patients. Female patients reported less sexual activity but fewer concerns - concordant with earlier studies [91].

In a small Polish study in early cancers (cT1N0-cT3N0) anorectal function after $5 \times 5$ Gy or CRT, followed by local excision, was worse than expected after a median of 20 months and little different to that experienced after anterior resection. Sexual functioning was worse after preoperative treatment and local excision in $19 \%$ of men, but no different in women [103].

\section{Chronic pain}

A Danish study reported that $31 \%$ of patients experienced chronic pain after surgery and the pain was associated with a reduced QOL [104]. Subsequent larger Danish population reports, which set out to develop a scoring system, also suggest a significant correlation between QOL assessment and the presence of major pain following radical surgery [105]. This latter study identified CRT as a significant risk factor for chronic pain after surgery (HR: 1.39; $\mathrm{p}=0.001)[105]$.

\section{Evidence from radiotherapy dose-escalated studies}

A non-randomized comparative effectiveness analysis using the National Oncology Data Alliance, suggests that patients with rectal cancer treated with higher radiotherapy doses were more likely to achieve a pCR, to have negative nodes at surgery and be down-staged from cT3-T4 and/or node positive disease to ypT0-T2N0 after neoadjuvant CRT [106]. However, long-term functional outcomes, LARS scores and QOL for patients achieving 'watch-and-wait' after standard doses of CRT (45-50 Gy) remain unclear - even more so in patients where the treatment has been dose-escalated. In addition, it may be relevant that some have modified standard field sizes to reduce late effects $[54,107]$.

The rectum is the main organ at risk if dose escalation is considered and anorectal function becomes crucial. Various functional tools have been used. The Danish trial reported excellent sphincter function, with 18 (72\%) of 25 patients at 1 year and $11(69 \%)$ of 16 patients at 2 years reporting no fecal incontinence [64]. Rectal bleeding was highlighted as an issue for patients. Recent long-term outcomes of this small prospective observational study in early tumors [64] have been presented in abstract [108]. The mature results are more reassuring in terms of local symptoms, but only 18 patients treated nonsurgically provide information regarding long-term PROs at the 5 years time-point and the data are not yet published.

In addition, we know nothing regarding QOL of the 33 patients who failed to respond or experienced regrowth. The Phase I Herbert dose-escalation trial included medically inoperable/elderly patients treated with an initial external beam radiotherapy to $39 \mathrm{~Gy}$ in 13 fractions, followed by brachytherapy weekly boosts of 5-8 Gy. With a median follow-up of 30 months, $60 \%$ of the cohort achieved cCR, with a 2-year freedom from local progression in 
$55 \%$ and regrowth in only $30 \%$. Toxicities were high with late grade 2 and $\geq 3$ proctitis occurring in 48 and $40 \%$, respectively [109].

\section{Ongoing \& future trials}

The STARTREC trial

The international multicenter Phase II/III STAR-TREC study (NCT02945566) aims to assess the feasibility of recruiting to a randomized trial, comparing radical surgery versus organ-preserving treatment using CRT or $5 \times 5$ Gy, followed by selective transanal microsurgery [54]. Patients are randomized on a 1:1:1 basis between standard radical surgical and organ-saving treatments. The real question here is what is the QOL in all of the patients in all three arms - not just those who respond and achieve organ sparing? The trial allows a comparison of QOL/function after surgery with no stoma, versus QOL after surgery with a permanent stoma, versus QOL after CRT and no radical surgery and no stoma. Hence, proposals to abandon the original randomization in STARTREC between CRT or short course pre-operative radiotherapy and radical surgery, risk losing this comparative data [110].

\section{The OPERA trial}

The OPERA trial (NCT02505750) is a randomized Phase III study for small early cancers (cT2, cT3a-b tumours $<5 \mathrm{~cm}$ ). A total of $45 \mathrm{~Gy}$ CRT is planned and then patients are randomized between either further boost with EBRT (9 Gy/5 fractions) or a brachytherapy boost using Papillon (90 Gy/3 fractions). A total of 236 patients are required. The primary end point is the rate of rectum preservation either with local excision or 'watch and wait' after neoadjuvant treatment, without non salvageable locally progressive disease at 3 years post treatment, or without a permanent stoma. The trial hypothesis is to increase organ preservation from 20 to $40 \%$ in the brachytherapy group (HR: 0.56) [111].

\section{The TRIGGER trial}

The TRIGGER trial in LARC NCT02704520 examines the feasibility of recruiting and randomizing into a trial, which offers different patient management according to radiological response to CRT (mrTRG) [112].

There are two other relevant trials. A trial from Vejle in Denmark (NCT0409529), which is examining radiation dose-escalation of small tumors $<4.5 \mathrm{~cm}$ with clinical tumor category cT1-cT3b.

The Morpheus trial from Quebec (NCT03051464) selects eligible smaller clinical T2-3 N0 rectal cancers $(<5 \mathrm{~cm}$ in size and with penetration less than $5 \mathrm{~mm}$ into the mesorectal fat, i.e., cT3b) and compares the use of either an external beam boost of $9 \mathrm{~Gy}$ or a brachytherapy boost of $30 \mathrm{~Gy}$ in three fractions following CRT. The primary end point is rectal preservation in treated patients and the number of participants that achieve a $\mathrm{cCr}$ at 2 years [113].

\section{Possible biomarkers to predict $\mathrm{pCR}$}

Analyses of molecular markers and molecular subtypes are not yet part of the everyday clinical setting in CRC. Yet, determination of genetic mutations and molecular-expression profiles are increasingly providing biomarkers to select the most appropriate treatments in many other cancers. There are clear advantages over traditional paradigms of clinical risk factors such as TNM stage, comorbidity and performance status. Robust biomarkers would allow appropriate selection and the tailoring of different treatments to specific subsets. This individualization could thereby avoid unnecessary exposure to toxic and ineffective treatments (CRT) in nonresponders and sidestep futile delays to surgery.

However, risk stratification of patients using the numerous available clinical features, routinely collected laboratory tests, biochemical pathological and molecular factors and multiparametric imaging, are not yet reliable in identifying patients with rectal cancer who are likely to achieve pCR or cCR after CRT. The poor performance of these models and the uncertainty as to how to integrate all the varying information suggests more research is required before we can be confident in our predictions.

\section{Conclusion}

In our view, enthusiasts treating patients, where there is no initial rationale for the use of preoperative CRT in terms of local control, appear to focus more on achieving organ preservation itself and early outcomes as the primary goal of treatment, rather than long-term survival, functional outcomes and QOL in the whole population treated. Outcomes likely to be relevant to patients, such as anorectal function, long-term toxicity and QOL, have been neglected. 
The majority of patients with early rectal cancer will be cured of their disease with radical treatment (whether surgery or radiotherapy). For this reason, we would encourage documenting the toxicities, functional changes and QOL and how these are best managed. Patient preferences are clearly crucial, and they need to well-informed.

Hence, if we are to get the best out of joint decision-making, both patients and health care professionals need to grasp not only the substantial benefits for those patients who achieve organ-sparing, but also the potential long-term and late adverse effects of all the different treatment options in the whole population. To date, there has been little appetite or expertise to focus on these.

\section{Future perspective}

In the future the field should move away from an enthusiast-led, to a more risk stratified, personalized medicine approach to treat rectal cancer - incorporating 'watch and wait' for the most appropriate patients and putting the patient at the center of the decision-making process. We need longer term data with regard to sustained response rates, the risk of metastases, OS, stoma rates, stoma reversal rates, sequelae of treatment and other QOL parameters. Ideally this will be done in the context of prospective randomized controlled trials - to enable us to predict for and select the most ideal patients for this approach.

Serum, molecular or genomic markers will hopefully offer us better confidence to select for those who are likely to achieve a cCR and/or greater clarity to select out those who will respond poorly to CRT. These biomarkers should allow for earlier decision-making and improved planning of more personalized patient pathways.

The advent of new or enhanced multi-parametric imaging techniques may also offer the ability to demonstrate more accurate concordance between cCR and cPR after CRT - and in turn predict for individualized risks of requiring salvage surgery.

\section{Executive summary}

- The oncological safety of a 'watch and wait' strategy in rectal cancer when complete clinical response is achieved after standard chemoradiation dose has been established, by retrospective data and large prospective databases.

- Data on long-term functional outcomes and quality of life after a 'watch and wait' organ sparing policy in rectal cancer remain sparse and insufficient to counsel patients.

- We do not, as yet, have the ability to accurately predict for response and select those who will benefit most from 'watch and wait.'

- Prospective trials are required to determine whether better oncological and similar functional outcomes are feasible with radiotherapy dose-escalation, different field sizes and additional chemotherapy.

- The likelihood of achieving complete clinical response after chemoradiotherapy is claimed to be higher for smaller earlier stage tumors - complete clinical response is likely to occur earlier, will be more clear-cut and easier to determine with certainty and more likely to be sustained for long term.

- It remains uncertain whether nonresponders to chemoradiation are disadvantaged by receiving an ineffective treatment which could render the tumor more aggressive.

- The potential consequences of treating patients, in whom preoperative chemoradiation is not usually considered necessary, include a higher risk of a permanent stoma than with surgery alone, an increased risk of hernia and worse functional outcomes for poor responders. These factors should be considered in decision-making.

\section{Author contributions}

All authors participated in the development of the manuscript by provision of data and references. Both authors drafted the manuscript, made critical revisions and approved the final manuscript.

\section{Financial \& competing interests disclosure}

R Glynne-Jones has received honoraria for lectures and advisory boards and has been supported in attending international meetings in the last 5 years by Merck, Pfizer, Sanofi-Aventis and Roche. He has also in the past received unrestricted grants for research from Merck-Serono, Sanofi-Aventis and Roche. N Bhuva has received honoraria for advisory boards and has been supported in attending international meetings in the last 5 years by Bristol-Myers Squibb and Amgen. The authors have no other relevant affiliations or financial involvement with any organization or entity with a financial interest in or financial conflict with the subject matter or materials discussed in the manuscript apart from those disclosed.

No writing assistance was utilized in the production of this manuscript. 


\section{Open access}

This work is licensed under the Attribution-NonCommercial-NoDerivatives 4.0 Unported License. To view a copy of this license, visit http://creativecommons.org/licenses/by-nc-nd/4.0/

\section{References}

Papers of special note have been highlighted as: $\bullet$ of interest; $\bullet \bullet$ of considerable interest

1. Gerard JP, Conroy T, Bonnetain F et al. Preoperative radiotherapy with or without concurrent fluorouracil and leucovorin in T3-T4 rectal cancers: results of FFCD 9203. J. Clin. Oncol. 24, 4620-4625 (2006).

2. Bosset JF, Calais G, Mineur L et al. Fluorouracil-based adjuvant chemotherapy after preoperative chemoradiotherapy in rectal cancer: long-term results of the EORTC 22921 randomised study. Lancet Oncol. 15, 184-190 (2014).

3. Brændengen M, Glimelius B. Preoperative radiotherapy or chemoradiotherapy in rectal cancer - is survival improved? An update of the "Nordic" LARC study in non-resectable cancers. Radiother. Oncol. 127(3), 392-395 (2018).

4. Rödel C, Graeven U, Fietkau R et al. . Oxaliplatin added to fluorouracil-based preoperative chemoradiotherapy and postoperative chemotherapy of locally advanced rectal cancer (the German CAO/ARO/AIO-04 study): final results of the multicentre, open-label, randomised, Phase 3 trial. Lancet Oncol. 16(8), 979-989 (2015).

5. Aschele C, Cionini L, Lonardi S et al. Primary tumor response to preoperative chemoradiation with or without oxaliplatin in locally advanced rectal cancer: pathologic results of the STAR-01 randomized Phase III trial. J. Clin. Oncol. 29(20), 2773-2780 (2011).

6. Gérard JP, Azria D, Gourgou-Bourgade S et al. Comparison of two neoadjuvant chemoradiotherapy regimens for locally advanced rectal cancer: results of the Phase III trial ACCORD 12/0405-Prodige 2. J. Clin. Oncol. 28(10), 1638-1644 (2010).

7. Allegra CJ, Yothers G, O'Conell MJ et al. Neoadjuvant 5-FU or capecitabine plus radiation with or without oxaliplatin in rectal cancer patients: a Phase III randomized clinical trial. J. Natl Cancer Inst. 107(11), (2015).

8. Schmoll HJ, Haustermans K, Price TJ et al. Preoperative chemoradiotherapy and postoperative chemotherapy with capecitabine $+/-$ oxaliplatin in locally advanced rectal cancer: Final results of PETACC-6. J. Clin. Oncol. 36(15), 3500-3500 (2018).

9. Deng Y, Chi P, Lan P et al. Modified FOLFOX6 with or without radiation versus fluorouracil and leucovorin with radiation in neoadjuvant treatment of locally advanced rectal cancer: initial results of the Chinese FOWARC multicenter, open-label, randomized three-arm Phase III trial. J. Clin. Oncol. 34(27), 3300-3307 (2016).

10. Sauer R, Becker H, Hohenberger W et al. . Preoperative versus postoperative chemoradiotherapy for rectal cancer. N. Engl. J. Med. 351, 1731-1740 (2004).

11. Glynne-Jones R, Harrison M, Hughes R. Challenges in the neoadjuvant treatment of rectal cancer: balancing the risk of recurrence and quality of life. Cancer Radiother. 17(7), 675-685 (2013).

12. Maas M, Nelemans PJ, Valentini $\mathrm{V}$ et al. Long-term outcome in patients with a pathological complete response after chemoradiation for rectal cancer: a pooled analysis of individual patient data. Lancet Oncol. 11(9), 835-844 (2010).

13. Lu JY, Xiao Y, Qiu HZ et al. Clinical outcome of neoadjuvant chemoradiation therapy with oxaliplatin and capecitabine or 5-fluorouracil for locally advanced rectal cancer. J. Surg. Oncol. 108, 213-219 (2013).

14. Fokas $\mathrm{E}$, Liersch $\mathrm{T}$, Fietkau $\mathrm{R}$ et al. Tumor regression grading after preoperative chemoradiotherapy for locally advanced rectal carcinoma revisited: updated results of the CAO/ARO/AIO-94 trial. J. Clin. Oncol. 32(15), 1554-1562 (2014).

15. Sauer R, Liersch T, Merkel S et al. Preoperative versus postoperative chemoradiotherapy for locally advanced rectal cancer: results of the German CAO/ARO/AIO-94 randomized Phase III trial after a median follow-up of 11 years. J. Clin. Oncol. 30(16), 1926-1933 (2012).

16. Kim CW, Kang BM, Kim IY et al. Korean Society of Coloproctology (KSCP) trial of cONsolidation Chemotherapy for Locally advanced mid or low rectal cancer after neoadjUvant concurrent chemoraDiothErapy: a multicenter, randomized controlled trial (KONCLUDE). BMC. Cancer 18(1), 538 (2018).

17. Garcia-Aguilar J, Chow OS, Smith DD et al. Effect of adding mFOLFOX6 after neoadjuvant chemoradiation in locally advanced rectal cancer: a multicentre, Phase 2 trial. Lancet Oncol. 16(8), 957-966 (2015).

-• The so called 'Timing Trial' which suggests that adding sequential cycles of FOLFOX increases pathological complete response rates up to $38 \%$ with six cycles.

18. Fokas E, Ströbel P, Fietkau R et al. . Tumor regression grading after preoperative chemoradiotherapy as a prognostic factor and individual-level surrogate for disease-free survival in rectal cancer. J. Natl Cancer Inst. 109(12), (2017).

19. Yothers G, George TJ, Petrelli NJ et al. Neoadjuvant rectal cancer (RC) score to predict survival: Potential surrogate endpoint for early phase trials. J. Clin. Oncol. 32 (5 Suppl; Abstract), 3533 (2014).

-• Initial study proposing neoadjuvant rectal (NAR) score as method of capturing response effects from chemoradiotherapy and total neoadjuvant treatment in all patients rather than just pathological complete response.

20. Fokas E, Fietkau R, Hartmann A German Rectal Cancer Study Group. et al. Neoadjuvant rectal score as individual-level surrogate for disease-free survival in rectal cancer in the CAO/ARO/AIO-04 randomized phase III trial. Ann. Oncol. 29(7), 1521-1527 (2018). 
21. Park IJ, You YN, Agarwal A et al. Neoadjuvant treatment response as an early response indicator for patients with rectal cancer. J. Clin. Oncol. 30(15), 1770-1776 (2012).

22. Li N, Jin J, Yu J et al. Down-staging depth score to predict outcomes in locally advanced rectal cancer achieving ypI stage after neoadjuvant chemo-radiotherapy versus de novo stage $\mathrm{pI}$ cohort: a propensity score-matched analysis. Chin. J. Cancer Res. 30(3), 373-381 (2018).

23. Fokas E, Liersch T, Fietkau R et al. Tumour down-staging after pre-operative chemoradiotherapy: the reverse "Will Rogers effect". Cancer 121(11), 1724-1727 (2015).

24. Bosset JF, Calais G, Mineur L et al. Enhanced tumorocidal effect of chemotherapy with preoperative radiotherapy for rectal cancer: preliminary results - EORTC 22921. J. Clin. Oncol. 23(24), 5620-5627 (2005).

25. Landriscina M, Maddalena F, Laudiero G, Esposito F. Adaptation to oxidative stress, chemoresistance, and cell survival. Antioxid. Redox Signal 11, 2701-2716 (2009).

26. Trumpi K, Ubink I, Trinh A et al. Neoadjuvant chemotherapy affects molecular classification of colorectal tumors. Oncogenesis 6(7), e357 (2017).

27. Bettoni F, Masotti C, Correa BR et al. The effects of neoadjuvant chemoradiation in locally advanced rectal cancer - the impact in intratumoral heterogeneity. Front. Oncol. 9, 974 (2019).

28. Bhangu A, Wood G, Brown G, Darzi A, Tekkis P, Goldin R. The role of epithelial mesenchymal transition and resistance to neoadjuvant therapy in locally advanced rectal cancer. Colorectal. Dis. 16(4), O133-O143 (2014).

29. Kojima M, Ishii G, Atsumi N, Nishizawa Y, Saito N, Ochiai A. CD133 expression in rectal cancer after preoperative chemoradiotherapy. Cancer Sci. 101(4), 906-912 (2010).

30. Sprenger T, Conradi LC, Beissbarth T et al. Enrichment of CD133-expressing cells in rectal cancers treated with preoperative radiochemotherapy is an independent marker for metastasis and survival. Cancer 119(1), 26-35 (2013).

31. Shikina A, Shinto E, Hashiguchi Y et al. Differential clinical benefits of 5-fluorouracil-based adjuvant chemotherapy for patients with stage III colorectal cancer according to CD133 expression status. Jpn J. Clin. Oncol. 2014, 44(1), 42-48 (2014).

32. Yahya J, Herzig D, Farrell M et al. Survey results of US radiation oncology providers' contextual engagement of watch-and-wait beliefs after a complete clinical response to chemoradiation in patients with local rectal cancer. J. Gastrointest. Oncol. 9(6), 1127-1132 (2018).

33. Glynne-Jones R, Hughes R. Complete response after chemoradiotherapy in rectal cancer (watch-and-wait): have we cracked the code? Clin. Oncol. 28(2), 152-160 (2016).

34. Habr-Gama A, Perez RO, São Julião GP, Proscurshim I, Gama-Rodrigues J. Non-operative approaches to rectal cancer: a critical evaluation. Semin. Radiat. Oncol. 21(3), 234-239 (2011).

35. National Bowel Cancer Audit Annual report 2018 (2018). www.nboca.org.uk/content/uploads/2018/12/NBOCA-annual-report2018.pdf

36. Verseveld M, de Graaf EJ, Verhoef C et al. CARTS Study Group. Chemoradiation therapy for rectal cancer in the distal rectum followed by organ-sparing transanal endoscopic microsurgery (CARTS study). Br. J. Surg.102(7), 853-860 (2015).

37. Roh MS, Colangelo LH, O'Connell MJ et al. Preoperative multimodality therapy improves disease-free survival in patients with carcinoma of the rectum: NSABP-R03. J. Clin. Oncol. 27, 5124-5130 (2019).

38. Bujko K, Nowacki MP, Nasierowska-Guttmejer A et al. Sphincter preservation following preoperative radiotherapy for rectal cancer: report of a randomised trial comparing short-term radiotherapy vs. conventionally fractionated radiochemotherapy. Radiother. Oncol. 72(1), 15-24 (2004).

39. Feddern ML, Jensen TS, Laurberg S.Chronic pain in the pelvic area or lower extremities after rectal cancer treatment and its impact on quality of life. A population-based, cross-sectional study. Pain 156(9), 1765-1771 (2015).

40. van Gijn W, Marijnen CA, Nagtegaal ID et al. Dutch Colorectal Cancer Group. Preoperative radiotherapy combined with total mesorectal excision for resectable rectal cancer: 12-year follow-up of the multicentre, randomised controlled TME trial. Lancet Oncol. 12(6), 575-582 (2011).

41. Bondeven P, Emmertsen KJ, Laurberg S, Pedersen BG. Neoadjuvant therapy abolishes the functional benefits of a larger rectal remnant, as measured by magnetic resonance imaging after restorative rectal cancer surgery. Eur. J. Surg. Oncol. 41(11), 1493-1499 (2015).

42. Stijns RCH, de Graaf EJR, Punt CJA. CARTS Study Group. Long-term oncological and functional outcomes of chemoradiotherapy followed by organ-sparing transanal endoscopic microsurgery for distal rectal cancer: the CARTS study. JAMA Surg. 154(1), 47-54 (2019).

43. Habr-Gama A, de Souza PM, Ribeiro U et al. Low rectal cancer: impact of radiation and chemotherapy on surgical treatment. Dis. Colon Rectum 41, 1087-96 (1998).

44. Habr-Gama A, Perez RO, Nadalin W et al. Operative versus nonoperative treatment for stage 0 distal rectal cancer following chemoradiation therapy: long-term results. Ann. Surg. 240(4), 711-717 (2004).

45. Habr-Gama A, Sabbaga J, Gama-Rodrigues J et al. Watch and wait approach following extended neoadjuvant chemoradiation for distal rectal cancer: are we getting closer to anal cancer management? Dis. Colon Rectum 56(10), 1109-17 (2013). 
-• Shows very high proportion of patients achieving complete clinical response after chemoradiotherapy and a high proportion have sustained complete clinical response.

46. Maas M, Beets-Tan RG, Lambregts DM et al. Wait-and-see policy for clinical complete responders after chemoradiation for rectal cancer. J. Clin. Oncol. 29(35), 4633-4640 (2011).

47. Martens MH, Maas M, Heijnen LA et al. Long-term outcome of an organ preservation program after neoadjuvant treatment for rectal cancer. J. Natl Cancer Inst. 108(12), pii: djw171 (2016).

48. Renehan AG, Malcomson L, Emsley R et al. Watch-and-wait approach versus surgical resection after chemoradiotherapy for patients with rectal cancer (the OnCoRe project): a propensity-score matched cohort analysis. Lancet Oncol. 17, 174-183 (2016).

49. van der Valk MJM, Hilling DE, Bastiaannet $\mathrm{E}$ et al. . Long-term outcomes of clinical complete responders after neoadjuvant treatment for rectal cancer in the International Watch \& Wait Database (IWWD): an international multicentre registry study. Lancet 391(10139), 2537-2545 (2018).

- Important international registry/database which has collected data on a large number of patients achieving complete clinical response and shows the strategy is reasonably safe as regrowth on a 'watch and wait' strategy can generally be salvaged by surgery.

50. Dossa F, Chesney TR, Acuna SA et al. A watch-and-wait approach for locally advanced rectal cancer after a clinical complete response following neoadjuvant chemoradiation: a systematic review and meta-analysis. Lancet Gastroenterol. Hepatol. 2, 501-513 (2017).

51. Chadi SA, Malcomson L, Ensor J et al. Factors affecting local regrowth after watch and wait for patients with a clinical complete response following chemoradiotherapy in rectal cancer (InterCoRe consortium): an individual participant data meta-analysis. Lancet Gastroenterol. Hepatol. 3(12), 825-836 (2018).

52. On J, Shim J, Aly EH. Systematic review and meta-analysis on outcomes of salvage therapy in patients with tumour recurrence during 'watch and wait' in rectal cancer. Ann. R. Coll. Surg. Engl. 11, 1-12 (2019).

53. Smith JJ, Chow OS, Gollub MJ et al. . Organ preservation in rectal adenocarcinoma: a Phase II randomized controlled trial evaluating 3-year disease-free survival in patients with locally advanced rectal cancer treated with chemoradiation plus induction or consolidation chemotherapy, and total mesorectal excision or non-operative management. BMC Cancer 15, 767 (2015).

54. Rombouts AJM, Al-Najami I, Abbott NL et al. . Can we Save the rectum by watchful waiting or TransAnal microsurgery following (chemo) Radiotherapy versus Total mesorectal excision for early REctal Cancer (STAR-TREC study)?: protocol for a multicentre, randomised feasibility study. BMJ Open 7(12), e019474 (2017).

- Description of the STARTREC trial taking early-stage patients with rectal cancer and delivering radiotherapy or chemoradiotherapy to achieve organ-sparing.

55. Smith JD, Ruby JA, Goodman KA et al. Nonoperative management of rectal cancer with complete clinical response after neoadjuvant therapy. Ann. Surg. 256(6), 965-972 (2012).

56. Nasir I, Fernandez L, Vieira P et al. Salvage surgery for local regrowths in watch \& wait - are we harming our patients by deferring the surgery? Eur. J. Surg. Oncol. 45(9), 1559-1566 (2019).

57. Habr Gama A São Julião GP, Vailati BB, Castro I, Raffaele D et al. Management of the complete clinical response. Clin Colon Rectal Surg.m 30(5), 387-39 (2017).

58. Lynn PB, Strombom P, Garcia-Aguilar J. Organ-preserving strategies for the management of near-complete responses in rectal cancer after neoadjuvant chemoradiation. Clin. Colon Rectal Surg. 30(5), 395-403 (2017).

59. Lindgren R, Hallböök O, Rutegård J, Sjödahl R, Matthiessen P. What is the risk for a permanent stoma after low anterior resection of the rectum for cancer? A six-year follow-up of a multicenter trial. Dis. Colon Rectum 54, 41-47 (2011).

60. Smith JJ, Strombom P, Chow OS et al. Assessment of a watch-and-wait strategy for rectal cancer in patients with a complete response after neoadjuvant therapy. JAMA. Oncol. 5(4), e185896 (2019).

61. Cercek A, Roxburgh CSD, Strombom P et al. Adoption of total neoadjuvant therapy for locally advanced rectal cancer. JAMA. Oncol. 4, e180071 (2018)

62. Goodman KA. Total neoadjuvant therapy for rectal cancer. Cancer Radiother. 22, 459-465 (2018).

63. Fernández-Martos C, Pericay C, Aparicio J et al. Phase II, randomized study of concomitant chemoradiotherapy followed by surgery and adjuvant capecitabine plus oxaliplatin (CAPOX) compared with induction CAPOX followed by concomitant chemoradiotherapy and surgery in magnetic resonance imaging-defined, locally advanced rectal cancer: grupo cancer de recto 3 study. J. Clin. Oncol. 28(5), 859-65 (2010).

64. Appelt AL, Pløen J, Harling H. High-dose chemoradiotherapy and watchful waiting for distal rectal cancer: a prospective observational study. Lancet Oncol. 16(8), 919-927 (2015).

-• Novel study showing small early cancers can be safely treated with dose-escalation of radiotherapy/brachytherapy, which increases the chance of organ-sparing with reasonable late function.

65. Garcia-Aguilar J, Shi Q, Thomas CR Jr et al. A Phase II trial of neoadjuvant chemoradiation and local excision for T2N0 rectal cancer: preliminary results of the ACOSOG Z6041 trial. Ann. Surg. Oncol. 19(2), 384-91 (2012). 
66. Gérard JP, Chamorey E, Gourgou-Bourgade $S$ et al. Clinical complete response (cCR) after neoadjuvant chemoradiotherapy and conservative treatment in rectal cancer. Findings from the ACCORD 12/PRODIGE 2 randomized trial. Radiother. Oncol. 115(2), 246-252 (2015).

67. Gérard JP, Barbet N, Gal J et al. Planned organ preservation for early T2-3 rectal adenocarcinoma: a French, multicentre study. Eur. J. Cancer 108, 1-16 (2019).

68. Habr-Gama A, Perez RO, Sabbaga J, Nadalin W, São Julião GP, Gama-Rodrigues J. Increasing the rates of complete response to neoadjuvant chemoradiotherapy for distal rectal cancer: results of a prospective study using additional chemotherapy during the resting period. Dis. Colon Rectum. 52(12), 1927-1934 (2009).

69. São Julião GP, Habr-Gama A, Vailati BB et al. Is neoadjuvant chemoradiation with dose-escalation and consolidation chemotherapy sufficient to increase surgery-free and distant metastases-free survival in baseline cT3 rectal cancer? Eur. J. Surg. Oncol. 44(1), 93-99 (2018).

70. National Bowel Cancer Audit, United Kingdom. Annual Report 2019 (2019). www.nboca.org.uk/reports/annual-report-2019/

71. Battersby NJ, Juul T, Christensen P. United Kingdom Low Anterior Resection Syndrome Study Group. Predicting the risk of bowel-related quality-of-life impairment after restorative resection for rectal cancer: a multicenter cross-sectional study. Dis. Colon Rectum 59(4), 270-280 (2016).

72. Emmertsen KJ, Laurberg S. Low anterior resection syndrome score: development and validation of a symptom-based scoring system for bowel dysfunction after low anterior resection for rectal cancer. Ann. Surg. 255(5), 922-928 (2012).

73. Pucciarelli S, Giandomenico F, De Paoli A. Bowel function and quality of life after local excision or total mesorectal excision following chemoradiotherapy for rectal cancer. Br. J. Surg. 104(1), 138-147 (2017).

74. Camilleri-Brennan J, Steele RJ. Objective assessment of morbidity and quality of life after surgery for low rectal cancer. Colorectal Dis. 4 , 61-66 (2002).

75. den Dulk M, Marijnen CA, Collette L et al. Multicentre analysis of oncological and survival outcomes following anastomotic leakage after rectal cancer surgery. Br. J. Surg. 96(9), 1066-1075 (2009).

76. Snijders HS, van den Broek CB, Wouters MW et al. An increasing use of defunctioning stomas after low anterior resection for rectal cancer. Is this the way to go? Eur. J. Surg. Oncol. 39(7), 715-720 (2013).

77. Zafar SN, Changoor NR, Williams K et al. Race and socioeconomic disparities in national stoma reversal rates. Am. J. Surg. 211(4), 710-715 (2016).

78. Gustafsson CP, Gunnarsson U, Dahlstrand U, Lindforss U. Loop-ileostomy reversal-patient-related characteristics influencing time to closure. Int. J. Colorectal Dis. 33(5), 593-600 (2018).

79. Åkesson O, Syk I, Lindmark G, Buchwald P. Morbidity related to defunctioning loop ileostomy in low anterior resection. Int. J. Colorectal Dis. 27(12), 1619-1623 (2012).

80. Tsunoda A, Tsunoda Y, Narita K, Watanabe M, Nakao K, Kusano M. Quality of life after low anterior resection and temporary loop ileostomy. Dis. Colon Rectum 51(2), 218-222 (2008).

81. Bhangu A, Nepogodiev D, Futaba K. Systematic review and meta-analysis of the incidence of incisional hernia at the site of stoma closure. World J. Surg. 36(5), 973-983 (2012).

82. Kuryba AJ, Scott NA, Hill J et al. Determinants of stoma reversal in rectal cancer patients who had an anterior resection between 2009 and 2012 in the English National Health Service. Colorectal Dis 18(6), 199-205 (2016).

83. Habr-Gama A, Lynn PB, Jorge JM et al. Impact of organ-preserving strategies on anorectal function in patients with distal rectal cancer following neoadjuvant chemoradiation. Dis. Colon Rectum 59(4), 264-269 (2016).

84. Hupkens BJP, Martens MH, Stoot JH et al. Quality of life in rectal cancer patients after chemoradiation: watch-and-wait policy versus standard resection 2 - a matched-controlled study. Dis. Colon Rectum 60(10), 1032-1040 (2017).

85. Vailati BB, Habr-Gama A, Mattacheo AE, São Julião GP, Perez RO. Quality of life in patients with rectal cancer after chemoradiation: watch-and-wait policy versus standard resection-are we comparing apples to oranges? Dis. Colon. Rectum 61(3), e21 (2018).

86. van der Sande ME, Hupkens BJP, Berbée M. Impact of radiotherapy on anorectal function in patients with rectal cancer following a watch and wait programme. Radiother. Oncol. 132, 79-84 (2019).

87. Sun W, Dou R, Chen J et al. Impact of long-course neoadjuvant radiation on postoperative low anterior resection syndrome and quality of life in rectal cancer: post hoc analysis of a randomized controlled trial. Ann. Surg. Oncol. 26(3), 746-755 (2019).

88. Pietrzak L, Bujko K, Nowacki MP Polish Colorectal Study Group. et al. Quality of life, anorectal and sexual functions after preoperative radiotherapy for rectal cancer: report of a randomised trial. Radiother. Oncol. 84(3), 217-25 (2007).

89. Stephens RJ, Thompson LC, Quirke P et al. Impact of short-course preoperative radiotherapy for rectal cancer on patients' uality of life: data from the Medical Research Council CR07/National Cancer Institute of Canada Clinical Trials Group C016 randomized clinical trial. J. Clin. Oncol. 28(27), 4233-4239 (2010).

90. Tiv M, Puyraveau M, Mineur L et al. Long-term quality of life in patients with rectal cancer treated with preoperative (chemo)-radiotherapy within a randomized trial. Cancer Radiother. 14(6-7), 530-534 (2010). 
91. Brændengen M, Tveit KM, Bruheim K, Cvancarova M, Berglund Å, Glimelius B. Late patient-reported toxicity after preoperative radiotherapy or chemoradiotherapy in nonresectable cancer: results from a randomized Phase III study. Int. J. Radiat. Oncol. Biol. Phys. 81(4), 1017-1024 (2011).

92. Wiltink LM, Chen TY, Nout RA et al. Health-related quality of life 14 years after preoperative short-term radiotherapy and total mesorectal excision for rectal cancer: report of a multicenter randomised trial. Eur. J. Cancer. 50(14), 2390-2398 (2014).

93. Russell MM, Ganz PA, Lopa $S$ et al. Comparative effectiveness of sphincter-sparing surgery versus abdominoperineal resection in rectal cancer: patient-reported outcomes in National Surgical Adjuvant Breast and Bowel Project randomized trial R-04. Ann. Surg. 261(1), 144-148 (2015).

94. McLachlan SA, Fisher RJ, Zalcberg J et al. The impact on health-related quality of life in the first 12 months: a randomised comparison of preoperative short-course radiation versus long-course chemoradiation for T3 rectal cancer (Trans-Tasman Radiation Oncology Group Trial 01.04). Eu.r J. Cancer 55, 15-26 (2016).

95. Chen TYT, Wiltink LM, Nout RA et al. Bowel function 14 years after preoperative short-course radiotherapy and total mesorectal excision for rectal cancer: report of a multicenter randomized trial. Clin. Colorectal Canc. 14, 106-114 (2014).

96. Kupsch J, Kuhn M, Matzel KE et al. To what extent is the low anterior resection syndrome (LARS) associated with quality of life as measured using the EORTC C30 and CR38 quality of life questionnaires? Int. J. Colorectal Dis. 34(4), 747762 (2019).

97. Guren MG, Eriksen MT, Wiig JN et al. . Quality of life and functional outcome following anterior or abdominoperineal resection for rectal cancer. Eur. J. Surg. Oncol. 31, 735-742 (2005).

98. D'Ambrosio G, Picchetto A, Campo $S$ et al. Quality of life in patients with loco-regional rectal cancer after ELRR by TEM versus VLS TME after nChRT: long-term results. Surg. Endosc. 33(3), 941-948 (2019).

99. Lange MM, van de Velde CJ. Urinary and sexual dysfunction after rectal cancer treatment. Nat. Rev. Urol. 8(1), 51-57 (2011).

100. Bregendahl S, Emmertsen KJ, Lindegaard JC, Laurberg S. Urinary and sexual dysfunction in women after resection with and without preoperative radiotherapy for rectal cancer: a population-based cross-sectional study. Colorectal Dis. 17(1), 26-37 (2015).

101. Marijnen CA, van de Velde CJ, Putter H et al. Impact of short-term preoperative radiotherapy on health-related quality of life and sexual functioning in primary rectal cancer: report of a multicenter randomized trial. J. Clin. Oncol. 23(9), 1847-1858 (2005).

102. Sauer R, Becker H, Hohenberger W et al. . Preoperative versus postoperative chemoradiotherapy for rectal cancer. N. Engl. J. Med. 351, 1731-1740 (2004).

103. Gornicki A, Richter P, Polkowski W et al. Anorectal and sexual functions after preoperative radiotherapy and full-thickness local excision of rectal cancer. Eur. J. Surg. Oncol. 40(6), 723-730 (2014).

104. Feddern ML, Jensen TS, Laurberg S. Chronic pain in the pelvic area or lower extremities after rectal cancer treatment and its impact on quality of life: a population-based cross-sectional study. Pain 156, 1765-1771 (2015).

105. Mortensen AR, Thyø A, Emmertsen KJ, Laurberg S. Chronic pain after rectal cancer surgery - development and validation of a scoring system. Colorectal Dis. 21(1), 90-99 (2019).

106. Hall MD, Schultheiss TE, Smith DD, Fakih MG, Wong JY, Chen YJ. Effect of increasing radiation dose on pathologic complete response in rectal cancer patients treated with neoadjuvant chemoradiation therapy. Acta Oncol. 55(12), 1392-1399 (2016).

107. Socha J, Pietrzak L, Zawadzka A, Paciorkiewicz A, Krupa A, Bujko K. A systematic review and meta-analysis of pT2 rectal cancer spread and recurrence pattern: Implications for target design in radiation therapy for organ preservation. Radiother. Oncol. 133, 20-27 (2019).

108. Dizdarevic E, Appelt AE, Hansen T et al. Long-term outcomes after high-dose chemoradiotherapy for non-surgical management of distal rectal cancer. J. Clin. Oncol 37(Suppl. abstr.), 3611 (2019).

109. Rijkmans EC, van Triest B, Nout RA et al. Evaluation of clinical and endoscopic toxicity after external beam radiotherapy and endorectal brachytherapy in elderly patients with rectal cancer treated in the HERBERT study. Radiother. Oncol. 126(3), 417-423 (2018).

110. STARTREC trial. https://clinicaltrials.gov/ct2/show/NCT02945566

111. Opera trial. https://clinicaltrials.gov/ct2/show/NCT02505750

112. Trigger trial. https://clinicaltrials.gov/ct2/show/NCT02704520

113. Morpheus trial. https://clinicaltrials.gov/ct2/show/NCT03051464 